\title{
An inguinal hernia imposter
}

\author{
RR Patel,,${ }^{1,2}$ (D) S Tu, ${ }^{3}$ iD J Plaskett ${ }^{2}$ iD \\ ${ }^{1}$ Department of General Surgery, Groote Schuur Hospital, South Africa \\ ${ }^{2}$ Department of General Surgery, Victoria Hospital, South Africa \\ ${ }^{3}$ Department of Anatomical Pathology, Groote Schuur Hospital, South Africa
}

Corresponding author, email: ravin.patel.3@gmail.com

\section{Summary}

This is a report of one of the many imposters of an irreducible inguinal hernia, a dermoid cyst. It is a rare entity that should be considered in the differential diagnosis of a groin lump when an atypical clinical presentation or groin examination occurs. Complete excision with histological evaluation remains the mainstay of surgical treatment.

Keywords: dermoid cyst, inguinal hernia, inguinal canal, incarcerated, hernia surgery

\section{Case report}

A 17-year-old male presented with a 10-year history of progressively enlarging left groin swelling, causing him mild local discomfort. He had no other symptoms and no significant past medical or surgical history.

Examination of his left inguinal area revealed a "mass" in the inguinal canal, just lateral to the symphysis pubis. The mass was irreducible, had a cough impulse and did not extend into the scrotum. The overlying skin was normal and there was minimal tenderness when pressure was applied. Abdominal examination was normal. A diagnosis of an irreducible inguinal hernia was made and he was scheduled for a hernia repair.

At surgery, a $4 \times 4 \mathrm{~cm}$ cystic structure was found in the inguinal canal, separate from the spermatic cord structures and attached medially to the pubic tubercle. The cyst was excised and no hernia defect or indirect sac were detected (Figure 1). Upon opening the cyst, thick yellow-brown sebum and hair, with an epithelialised internal lining was encountered.
Histological examination confirmed a dermoid cyst, lined by stratified squamous epithelium with hair follicles and associated sebaceous and apocrine glands (Figure 2). ${ }^{1}$

\section{Discussion}

Swellings of the inguinal region are common referrals to surgical services. The most common cause is an inguinal hernia. Undescended testes, hydroceles, spermatic cord lipomas, blood aneurysms, saphena varix, lymph nodes, psoas abscess, neurofibromas, sebaceous, pilonidal, epidermoid and dermoid cysts are amongst a host of potential pathologies. ${ }^{2-5}$

Dermoid cysts typically occur when there is sequestration of cutaneous tissue (ectoderm) along the lines of embryonal fusion. They are most often found in or deep to the skin on the scalp, face, neck and anterior chest with a preponderance for the midline. Dermoid cysts can also be intracranial, intraspinal, perispinal or intra-abdominal where they usually involve the ovary.

Typically lined with stratified squamous epithelium, the hallmark feature of a dermoid cyst is the pilosebaceous unit

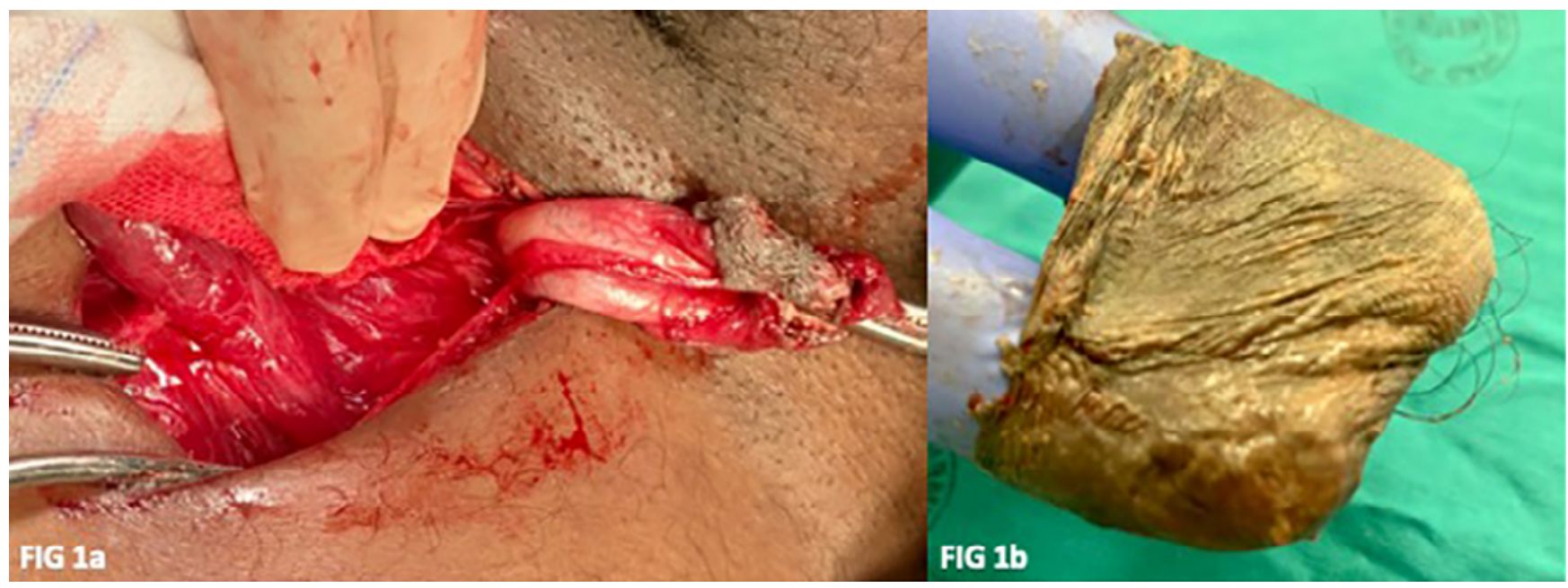

Figure 1a: Dissection of dermoid cyst from within inguinal canal, adherent to pubic tubercle (cyst lining visible)
Figure 1b: Excised everted cyst showing squamous epithelial lining and hair 


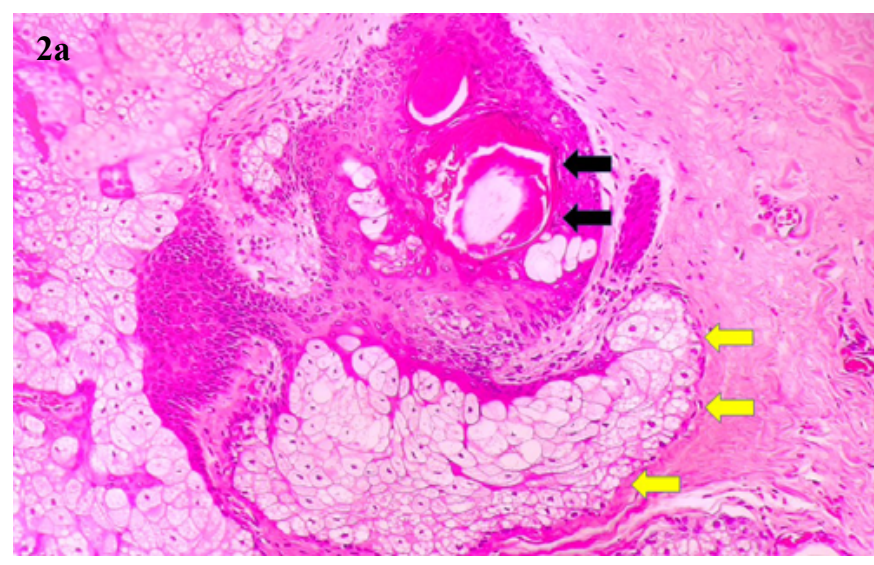

Figure 2a: Low power view showing a cyst lined by epithelium (yellow arrows), section of a hair follicle, hair bulb (black arrows) and associated sebaceous glands in the wall of the cyst

that differentiates it from an epidermoid cyst. The presence of hair and sebum within the cyst in our case supports this histological finding. ${ }^{1,6}$

There have been eight reported cases of dermoid cysts within the inguinal canal, mimicking an inguinal hernia with no gender bias. Their ages ranged from 18 to 72 years old, making this case the youngest reported at 17 years of age. The duration of symptoms reported ranged from 1 to 5 years, making this case the longest reported history with 10 years of symptomatology. ${ }^{7}$ Malignant transformation in a dermoid cyst is rare (less than $2 \%$ ) and is usually seen in those occurring in the ovaries and testes. Squamous cell carcinoma is the most common malignancy, followed by adenocarcinoma. ${ }^{6}$

Surgical exploration with complete excision of the cyst remains the treatment of choice, especially if the cyst is symptomatic. Preoperative diagnosis is not always possible, and discovery is often intraoperatively at the planned inguinal hernia repair. Preoperative imaging with ultrasound, computed tomography or magnetic resonance imaging can distinguish a cyst from a hernia when groin examination is atypical, ${ }^{8}$ but the final arbiter remains surgical exploration, complete removal and cyst histology. $2,9,10$

\section{Conflict of interest}

The authors declare no conflict of interest.

\section{Funding source}

No funding was required.

\section{Ethical approval}

The authors declare that this submission is in accordance with the principles laid down by the Responsible Research Publication Position Statements as developed at the $2^{\text {nd }}$ World Conference on Research Integrity in Singapore, 2010. Informed written consent was obtained from the patient in the case study. No ethical approval was required for this case report.

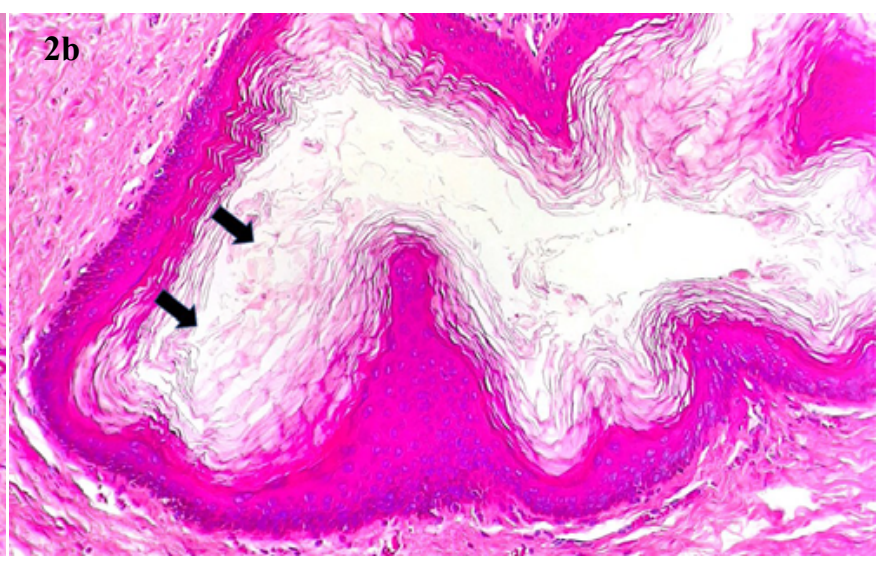

Figure 2b: High power view showing a cyst lining comprising stratified squamous epithelium with laminated keratinous material (arrows)

\section{ORCID}

RR Patel (iD https://orcid.org/0000-0002-7097-4527

$\mathrm{S} \mathrm{Tu}$ (D) https://orcid.org/0000-0002-9080-0559

J Plaskett (ID https://orcid.org/0000-0002-9917-3475

\section{REFERENCES}

1. Lindberg M, Lamps L. Diagnostic pathology, normal histology. 2nd ed. Salt Lake City: Elsevier Inc; 2017. p. 51-3.

2. Salemis NS, Karagkiouzis G, Sambaziotis D, Tsiambas E. Large dermoid cyst of the spermatic cord presenting as an incarcerated hernia - a rare presentation and literature review. Hernia. 2010;14:321-3.

3. Antonino A, Lovisetto F, Corradini C, De Cesare F. Preperitoneal dermoid cyst simulating a direct inguinal hernia - case report. Med Rep Case Stud. 2016;1:116. https://doi.org/ 10.4172/2572-5130.10001162016.

4. Das S, De U, Das D, Sarkar S. Inguinal dermoid cyst masquerading as irreducible inguinal hernia - a case report. Int J Case Rep Imag. 2012;3(9):54-6.

5. Bülent Y, Özüpek D, Tuğba E, et al. Dermoid cyst of the round ligament misdiagnosed as inguinal hernia. J Turk Ger Gynecol Assoc [Internet]. 2016;17:S106-7. Available from: http://www.embase.com/search/results?subaction=viewrecor $\mathrm{d} \&$ from=export\&id=L612656193.

6. Jayasuriya NSS, Siriwardena S, Tilakaratne WM, Parthiepan S. Malignant transformation of a long-standing submental dermoid cyst to a carcinosarcoma - a case report. J Med Case Rep. 2017;11(1):1-4. https://doi.org/10.1186/s13256-016-11 86-y.

7. Chandrakant R, Kesari S, Lakkanna R, Ashok A. Dermoid cyst of the inguinal canal masquerading as irreducible inguinal hernia: a case report with review of literature. J Evol Med Dent Sci. 2013;2(11):1567-71.

8. Park HR, Bin Park SB, Lee ES, Park JH. Sonographic evaluation of inguinal lesions. Clinical Imaging. 2016;40(5):949-55. https://doi.org/10.1016/j.clinimag.2016.04.017.

9. Leeming R, Olsen M, Ponsky JL. Inguinal dermoid cyst presenting as an incarcerated inguinal hernia. J Pediatr Surg. 1992;27(1):117-8.

10. Meher S, Baijal M, Soni V, et al. Epidermoid cyst at a rare location, as a content of inguinal hernia - a case report with a review of the literature. J Minim Access Surg. 2016;12(3):2868. 